\title{
Duration of Dosing
}

National Cancer Institute

\section{Source}

National Cancer Institute. Duration of Dosing. NCI Thesaurus. Code C90378.

The interval of time over which a course of doses occurs. 